University of Nebraska - Lincoln

DigitalCommons@University of Nebraska - Lincoln

Demographic Risk Factors for Severe and Fatal Vivax and Falciparum Malaria Among Hospital Admissions in Northeastern Indonesian Papua

\author{
Mazie J. Barcus \\ Hasan Basri \\ Family Health International, hbasri@fhi.or.id \\ Helena Picarima \\ Family Health International \\ C. Manyakori \\ R.S. Persahabatan \\ Sekartuti \\ Puslitbang Biomedis \& Farmasi
}

See next page for additional authors

Follow this and additional works at: https://digitalcommons.unl.edu/usnavyresearch

Barcus, Mazie J.; Basri, Hasan; Picarima, Helena; Manyakori, C.; Sekartuti; Elyazar, Iqbal; Bangs, Michael J.; Maguire, Jason D.; and Baird, J. Kevin, "Demographic Risk Factors for Severe and Fatal Vivax and Falciparum Malaria Among Hospital Admissions in Northeastern Indonesian Papua" (2007). U.S. Navy Research. 62.

https://digitalcommons.unl.edu/usnavyresearch/62

This Article is brought to you for free and open access by the U.S. Department of Defense at DigitalCommons@University of Nebraska - Lincoln. It has been accepted for inclusion in U.S. Navy Research by an authorized administrator of DigitalCommons@University of Nebraska - Lincoln. 


\section{Authors}

Mazie J. Barcus, Hasan Basri, Helena Picarima, C. Manyakori, Sekartuti, Iqbal Elyazar, Michael J. Bangs, Jason D. Maguire, and J. Kevin Baird 


\title{
Demographic Risk Factors for Severe and Fatal Vivax and Falciparum Malaria Among Hospital Admissions in Northeastern Indonesian Papua
}

\author{
Mazie J. Barcus,* Hasan Basri, Helena Picarima, C. Manyakori, Sekartuti, Iqbal Elyazar, Michael J. Bangs, \\ Jason D. Maguire, and J. Kevin Baird \\ US Naval Medical Research Unit \#2, Jakarta, Indonesia; US Naval Medical Research Unit \#2, Jayapura, Papua, Indonesia; Provincial \\ Public Hospital, Jayapura, Papua, Indonesia; National Institute for Health Research and Development, Jakarta, Indonesia
}

\begin{abstract}
Between January 1998 and December 2000, the Jayapura Provincial Public Hospital in northeastern Indonesian New Guinea (Papua) admitted 5,936 patients with a diagnosis of malaria. The microscopic diagnosis at admission was Plasmodium falciparum (3,976, 67\%), Plasmodium vivax (1,135, 19\%), Plasmodium malariae $(8,<1 \%)$, and mixed species infections $(817,14 \%)$. Approximately $9 \%(367)$ of patients were classified as having severe malaria (277 P. falciparum, 36 P. vivax, 53 mixed infections, and 1 P. malariae) and 88 died (79 P. falciparum/mixed infections and $9 P$. vivax). Risk of fatal outcomes among severe malaria patients was indistinguishable between those with falciparum versus vivax malaria $(\mathrm{OR}=0.89 ; P=0.771)$. Compared with non-pregnant women, pregnant women showed no higher risk of severe malaria $(P=0.643)$ or death caused by severe malaria $(P=0.748)$. This study compares admissions per population (based on census data), parasitemia, morbidity, and mortality among children versus adults, pregnant versus non-pregnant women, and urban/suburban versus rural residents.
\end{abstract}

\section{INTRODUCTION}

Chronic, heavy exposure to plasmodia induces a naturally acquired immunity that diminishes parasite burden and attendant risk of disease and death. ${ }^{1}$ The distinctive epidemiology of malaria in intense transmission endemic settings has been thoroughly documented. ${ }^{2}$ Relatively few studies document the epidemiology of malaria in the setting of unstable transmission where few people have had prior exposure sufficient for onset or maintenance of protective immunity. We previously reported on the risk of severe morbidity and mortality among non-immune migrants to Indonesian New Guinea. ${ }^{3,4}$ In contrast to the marked susceptibility of young children in hyper- and holoendemic areas, we found adults to be significantly more susceptible to severe disease than children experiencing the same burden of infection. This pattern changed after a year or two, with onset of age-dependent immunity to high-density parasitemia and fever. ${ }^{5-7}$

We examined 3 years of records of admissions for malaria at the provincial hospital in Jayapura, Papua (formerly known as Irian Jaya), Indonesia. The catchment area for this hospital encompassed $63,000 \mathrm{~km}^{2}$ and a population of $\sim 338,000$, including sparsely populated rural areas with moderate to intense perennial malaria transmission and densely populated urban/suburban areas of relatively low risk. ${ }^{8}$ Across this spectrum of exposure and acquired immunity, we sought to identify demographic risk factors for poor outcomes with malaria. We also examined reported morbidity and mortality caused by Plasmodium vivax.

\section{MATERIALS AND METHODS}

Study area. Jayapura District is located in the northeastern corner of Papua, Indonesia, and is home of the provincial capital Jayapura and nearby satellite towns (Figure 1). The urban and suburban environments have a relatively low risk of malaria transmission compared with surrounding rural areas. The population density in the urbanized and developed

* Address correspondence to Mazie J. Barcus, 2061 Winged Foot Court, Reston, VA 20191. E-mail: mazie_barcus@yahoo.com areas is $245 / \mathrm{km}^{2}{ }^{9}$ compared with $4 / \mathrm{km}^{2}$ in the surrounding forested landscape covering $\sim 60,000 \mathrm{~km}^{2}$. Dense primary and secondary forest closely surround the scattered but substantial settlement schemes and smaller villages ( $\sim 60,000$ people) in the hinterlands of Jayapura (Figure 1). Rural areas just a few kilometers from Jayapura carry significant risk of malaria. ${ }^{10,11}$ Plasmodium falciparum is the dominant species, followed closely by Plasmodium vivax and distantly by Plasmodium malariae and Plasmodium ovale. Members of the Anopheles punctulatus species complex transmit malaria in this region. These mosquitoes typically favor open, sun-lit larval habitats (e.g., tracts cleared of forest that characterize most settlements in the region). ${ }^{12}$ These mosquitoes appear far less frequently in urbanized areas, apparently precluded by strong preferences for relatively pristine natural environments. Therefore, risk of exposure to biting anophelines vastly increases in rural environments and in village settings rather than forest interior. Vector mosquitoes in settlements transmit malaria to children and adults with equal frequency. ${ }^{13,14}$

Study hospital. The Rumah Sakit Umum Propinsi (RSUP, Provincial Public Hospital) in Jayapura is a 350-bed tertiary care facility operated by the provincial health service. It provides care to $\sim 110,000$ patients annually, admitting roughly $10 \%$ of cases. The RSUP receives patients directly, as well as those referred from secondary hospitals and clinics located at other nearby urban areas or settlements in outlying rural areas (Figure 1). Annually, malaria accounts for $\sim 15 \%$ of all hospitalizations (i.e., 2,000 malaria admissions/yr). RSUP operated a clinical laboratory that collected and examined Geimsa-stained blood films from patients with fever or otherwise suspected as having malaria as a matter of routine. We did not evaluate the competency of the staff malaria microscopists at RSUP, and we are not aware of any such standardized examination. Nonetheless, the microscopists were known as reliable on the basis of numerous collaborations over $>15$ years of malaria research in the Jayapura area. A recently conducted microscopy refresher training course found that the microscopists at RSUP hospital qualified as either competent or expert in objective, blinded pre-training evaluations in diagnosis of malaria. Moreover, none committed the error 


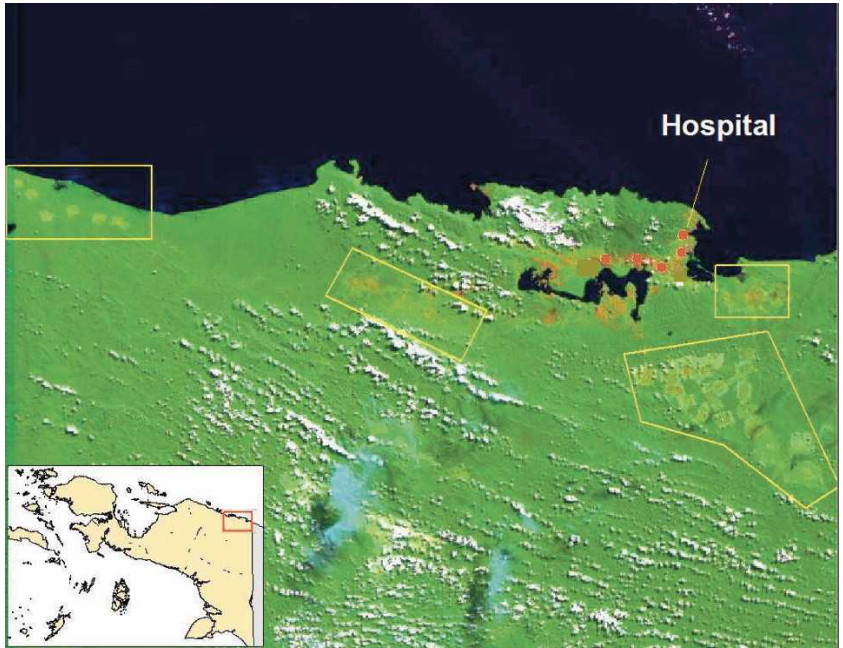

FIGURE 1. Satellite image of northeastern Papua showing urban centers (red dots, left to right) of Sentani, Abepura, Kotaraja, Angkasa, and Jayapura (hospital). Yellow boxes indicate settlements in forested areas (from left to right) of Armopa, Genyem, Arso, and Holtekam. Inset shows position of the area within Papua Province as a whole (LandSat image taken in 2000).

of diagnosing falciparum malaria as $P$. vivax in either pretraining or post-training examinations (Din Syafruddin, personal communication).

Record review. During 2001 and 2002, we reviewed records of patients admitted to RSUP with a slide-confirmed diagnosis of malaria between January 1998 and December 2000. A single study physician (HP) collected records from the RSUP archive and recorded the month of admission, age, pregnancy status, ethnicity, location of residence, clinical presentation, parasitologic findings, duration of hospital stay, treatment, and outcome. Records consisted of standard hospital patient treatment folders, each with a unique hospital identification number. Nurses and physicians recorded patient demography, signs and symptoms, laboratory results, and treatment plans on standard forms. All patients received a microscopic diagnosis of malaria by Giemsa-stained blood smear and a hemoglobin test for anemia. A total of 5,936 records were reviewed. The physician classified cases as "severe" on the basis of documented evidence of one or more criteria of the World Health Organization (WHO) definition of severe malaria. ${ }^{15}$ The data were double entered into digital databases and discrepancies corrected by re-examining records. A corrected, final database was locked (by "read only" measures) and used in all of the analyses reported herein.

Statistical analyses. Incidence calculations are based on 2000 population data compiled by the Provincial Population Statistics Office. ${ }^{16}$ Twenty-eight districts in the province comprised the hospital catchment population. We defined 4 of the 28 districts as urban on the basis of population density $>$ 100/km²: Jayapura Utara (north), Jayapura Selatan (south), Abepura, and Sentani. Hospital staff graded parasitemia on the four-point "plus system" scale (Appendix 1) where 0 is negative for infection and 4 is $>10$ parasites per thick film field. ${ }^{17}$ We defined high-grade parasitemia as a score $>3$ (the median score for both $P$. falciparum and P. vivax). Gametocytemia is defined as the presence of any sexual stage para- site. Seven clinical symptoms of malaria included fever, chills, headache, nausea, vomiting, myalgia, and weakness. Our record review failed to find residence data for 90 patients, pregnancy status for 122 women of childbearing age, and outcome data for 2 patients diagnosed with severe malaria. Cases without residence data were removed from analyses comparing urban versus rural residents. Cases without known pregnancy status were removed from analyses comparing pregnant and non-pregnant women. Cases without outcome data were removed from analyses involving death statistics. For mean comparisons, we report two-tailed $P$ values from the independent samples $t$ test. Odds ratios and $P$ values for comparison of rates and proportions were calculated using $\chi^{2}$ contingency tables. Analysis was performed using SPSS version 9.0.0 (Chicago, IL) and EpiInfo2000 Version 1.1.2 (Atlanta, GA).

\section{RESULTS}

Over the 36-month period, the hospital admitted 5,936 patients with a diagnosis of malaria. The microscopic diagnosis at admission for these patients was: Plasmodium falciparum $(3,976,67 \%), P$. vivax $(1,135,19 \%), P$. malariae $(8,<1 \%)$, and mixed species infections $(817,14 \%)$.

Demography. More than $60 \%$ of patients originated from other areas of Indonesia (18\% from Java or Bali, $42 \%$ from other Indonesian islands, and $<1 \%$ outside the country). $\mathrm{Na}$ tive Papuans comprised $38 \%$ of patients, with $78 \%$ of these coming from malaria endemic lowland areas and $22 \%$ from typically nonmalarious highland ( $>2,000 \mathrm{~m}$ above sea level) locations. Table 1 compares the age distribution of patients admitted for malaria to that of the general population of the province of Papua in 2000. The proportion of youngest children ( $<4$ years of age) and adults ( $>15$ years) among hospitalized patients was higher than in the general population $(P<0.001$ and $P=0.007$, respectively), whereas older children (5-15 years) were under-represented among hospitalized patients $(P<0.001)$.

Table 2 summarizes the demographic characteristics of hospitalized children versus adults, pregnant versus nonpregnant women, and rural versus urban residents. The patient records of 1,727 children and 4,209 adults were evaluated. Patient mean ages were 6 and 30 years, respectively. Hospitalized women of childbearing age $(1,921 \geq 13$ years) were classified as either pregnant (380) or non-pregnant $(1,419)$, with mean ages of 26 and 30 years, respectively $(P<$ $0.001)$. Pregnancy status was unrecorded in 122 cases. Patients from rural areas represented 726 cases, and 5,120 patients reported residing in urban/suburban areas, with mean ages of 21 and 23 years, respectively $(P<0.001)$.

TABLE 1

Age distribution of patients hospitalized in Jayapura, Indonesia, from 1998 through 2000

\begin{tabular}{cccc}
\hline Age group & Patients (\%) & Population $(\%)^{*}$ & $P$ value \\
\hline $0-4$ & $944(16)$ & $292(12)$ & $<0.001$ \\
$5-9$ & $319(5)$ & $245(10)$ & $<0.001$ \\
$10-15$ & $464(8)$ & $230(10)$ & 0.003 \\
$>15$ & $4,209(71)$ & $1,594(68)$ & 0.007 \\
\hline
\end{tabular}

* Thousands of people, from 2000 census figures for entire Province of Papua. ${ }^{16}$ 
TABLE 2

Demographic characteristics of enrolled patients stratified by age, pregnancy status, and location of residence

\begin{tabular}{lccc}
\hline \multicolumn{1}{c}{ Groups } & Number evaluated & Mean age & Male:female \\
\hline Children & 1,727 & 6 & 1.29 \\
Adults & 4,209 & 30 & 1.31 \\
$P$ value & - & - & 0.686 \\
Pregnant $\dagger$ & 380 & 26 & - \\
Not pregnant $\dagger$ & 1,419 & 30 & - \\
$P$ value & - & $<0.001$ & - \\
Rural* & 726 & 21 & 1.47 \\
Urban/suburban* & 5,120 & 23 & 1.28 \\
$P$ value & - & $<0.001$ & 0.090 \\
\hline
\end{tabular}

* Ninety case residences unknown/not recorded.

$\dagger$ Pregnancy status unknown/not recorded for 122 women of childbearing ages.

Parasitology. Table 3 lists the parasitologic characteristics of hospitalized children versus adults, pregnant versus nonpregnant women, and rural versus urban residents. The median parasite score (based on WHO four-point graded scale) was 3 for both $P$. falciparum and $P$. vivax. The ratio of $P$. falciparum to $P$. vivax was significantly $(P<0.001)$ less among children versus adults $(2.7: 1$ versus $3.9: 1 ; P<0.001)$. Risk of high-grade parasitemia ( $>3$ point score) was higher among children versus adults infected by $P$. falciparum $(56 \%$ versus $46 \%$; OR $=1.51, P<0.0001)$, and by $P$. vivax $(25 \%$ versus $18 \%$; OR $=1.49, P<0.001)$. The proportion of blood films showing gametocytemia was significantly higher among children than adults $(37 \%$ versus $26 \% ; P<0.001)$.

The ratio of $P$. falciparum to $P$. vivax was significantly lower among pregnant women compared with non-pregnant women (2.6:1 versus $3.7: 1 ; P=0.017)$. Pregnant women had no significantly greater risk of high-grade $P$. falciparum (54\% versus $48 \%$ ) or $P$. vivax (14\% versus $19 \%)$ parasitemia $(\mathrm{OR}=1.24, P=0.103$ and $\mathrm{OR}=0.72, P=0.224$, respectively); however, the gametocyte rate was significantly higher compared with non-pregnant women $(36 \%$ versus $26 \% ; P<$ $0.001)$.

The ratio of $P$. falciparum to $P$. vivax was 3.5:1 for both rural and urban residents. Rural residents showed lower risk of high-grade $P$. falciparum parasitemia (44\% versus $50 \%$; $\mathrm{OR}=0.79, P=0.008)$, but equal risk for high-grade $P$. vivax parasitemia $(18 \%$ versus $21 \%$; OR $=0.87, P=0.442)$. The proportion of blood films showing gametocytemia was significantly higher among rural residents $(33 \%$ versus $28 \% ; P=$ 0.019).

TABLE 3

Demographic characteristics of enrolled patients stratified by age, pregnancy status, and location of residence

\begin{tabular}{|c|c|c|c|c|}
\hline \multirow[b]{2}{*}{ Groups } & \multirow{2}{*}{$\begin{array}{l}\text { P. falciparum: } \\
P \text {. vivax ratio }\end{array}$} & \multicolumn{2}{|c|}{ Odds of high parasitemia* } & \multirow{2}{*}{$\begin{array}{l}\text { Gametocyte } \\
\text { rate }(\%)\end{array}$} \\
\hline & & P. falciparum & P. vivax & \\
\hline Children & $2.7: 1$ & \multirow{2}{*}{0.51} & \multirow{2}{*}{1.49} & 37 \\
\hline Adults & 3.9:1 & & & 26 \\
\hline$P$ value & $<0.001$ & $<0.0001$ & $<0.001$ & $<0.001$ \\
\hline Pregnant & 2.6:1 & \multirow{2}{*}{1.24} & \multirow{2}{*}{0.72} & 36 \\
\hline Not pregnant & $3.7: 1$ & & & 26 \\
\hline$P$ value & 0.017 & 0.103 & 0.224 & $<0.001$ \\
\hline Rural & $3.5: 1$ & \multirow{2}{*}{0.79} & \multirow{2}{*}{0.87} & 33 \\
\hline Urban/suburban & $3.5: 1$ & & & 28 \\
\hline$P$ value & 0.959 & 0.008 & 0.442 & 0.019 \\
\hline
\end{tabular}

Clinical presentation and outcomes. The most commonly reported complaints were fever $(87 \%)$, vomiting $(55 \%)$, nausea $(22 \%)$, headache $(18 \%)$, chills $(16 \%)$, malaise $(11 \%)$, and vertigo (11\%). Table 4 summarizes clinical presentation and outcomes among children versus adults, pregnant versus non-pregnant women, and residents of rural versus urban/ suburban areas.

Children reported vomiting, nausea, headache, and vertigo significantly less often than adults $(36 \%$ versus $62 \%$, OR = $0.35, P<0.0001 ; 5 \%$ versus $29 \%$, OR $=0.13, P<0.0001$; $7 \%$ versus $22 \%$, OR $=0.26, P<0.0001$; and $3 \%$ versus $14 \%$, $\mathrm{OR}=0.18, P<0.0001$, respectively). Adults more often presented with three or more symptoms consistent with malaria (43\% versus $11 \%$; OR $=6.1, P<0.001)$. Anemia $(<8$ $\mathrm{g} / \mathrm{dL}$ ) was reported as a feature of disease in $22 \%$ of children but only $6 \%$ of adults $(\mathrm{OR}=4.9, P<0.001)$. The proportion of patients classified as having severe malaria was $10 \%$ of children versus $5 \%$ of adults $(P<0.001)$. The death rate among children with reported severe malaria was $16 \%$ versus $31 \%$ among adults $(P=0.0006)$.

Pregnant women presented less often with three or more clinical symptoms consistent with malaria (26\% versus $40 \%$ ) compared with non-pregnant women $(P<0.001)$. Anemia was reported in $13 \%$ of pregnant women and $9 \%$ of nonpregnant women $(P=0.006)$. No differences appeared between pregnant and non-pregnant women classified as having severe malaria (both $3 \%$, OR $=1.16,95 \% \mathrm{CI}=0.59-2.26$ ). The death rate among pregnant women with severe malaria was $38 \%$ compared with $33 \%$ among non-pregnant women $(\mathrm{OR}=1.25,95 \% \mathrm{CI}=0.27-5.38)$.

People living in rural areas were less likely to have reported three or more complaints consistent with malaria compared with those living in urban or suburban areas $(30 \%$ versus $35 \%, P=0.010)$. Anemia was reported as a feature of disease in $20 \%$ of people living in rural areas compared with $9 \%$ among those living in urban/suburban zones $(P<0.001)$. The proportion of rural residents classified as having severe malaria was $10 \%$ versus $6 \%$ among urban/suburban dwellers $(P<0.001)$. The death rate among rural residents with severe malaria was $17 \%$ compared with $27 \%$ among urban/suburban dwellers $(P=0.083)$.

The overall proportion of cases classified as having severe malaria was $6 \%(367 / 5,936)$. The proportion of cases classified as severe was $7 \%(277 / 3,976)$ for $P$. falciparum, $3 \%(36 /$ $1,135)$ for $P$. vivax, and 6\% (53/817) for mixed infections. One

TABLE 4

Clinical presentations and outcomes among admitted patients by age, sex, pregnancy, and location of residence

\begin{tabular}{lccccc}
\hline \multicolumn{1}{c}{ Groups } & $\begin{array}{c}\text { Symptoms } \\
\text { of malaria* }\end{array}$ & $\begin{array}{c}\geq 3 \\
\text { complaints }\end{array}$ & Anemia & $\begin{array}{c}\text { Severe } \\
\text { malaria }\end{array}$ & $\begin{array}{c}\text { Fatal } \\
\text { outcome } \\
\text { with severe } \\
\text { malaria }\end{array}$ \\
\hline Children & 1.6 & $11 \%$ & $22 \%$ & $10 \%$ & $16 \%$ \\
Adults & 2.3 & $43 \%$ & $6 \%$ & $5 \%$ & $31 \%$ \\
$\quad P$ value & $<0.001$ & $<0.001$ & $<0.001$ & $<0.001$ & 0.0006 \\
Pregnant & 1.9 & $26 \%$ & $13 \%$ & $3 \%$ & $38 \%$ \\
Not pregnant & 2.3 & $40 \%$ & $9 \%$ & $3 \%$ & $33 \%$ \\
$P$ value & $<0.001$ & $<0.001$ & 0.006 & 0.643 & 0.748 \\
Rural* & 2.1 & $30 \%$ & $20 \%$ & $10 \%$ & $17 \%$ \\
Urban/suburban* & 2.0 & $35 \%$ & $9 \%$ & $6 \%$ & $27 \%$ \\
$P$ value & $<0.001$ & 0.010 & $<0.001$ & $<0.001$ & 0.083 \\
\hline * Mean number of complaints per seven clinical categories recorded (fever, chills, head- \\
ache, nausea, vomiting, myalgia, and weakness).
\end{tabular}


TABLE 5

Clinical presentations and outcome of severe malaria cases caused by $P$. falciparum $(n=330)$ or $P$. vivax $(n=36)$

\begin{tabular}{|c|c|c|c|c|}
\hline & \multicolumn{2}{|c|}{ Survived } & \multicolumn{2}{|c|}{ Died } \\
\hline & P. falciparum* & P. vivax & P. falciparum* & P. vivax \\
\hline Total severe malaria cases & 251 & 27 & 79 & 9 \\
\hline Unconscious (cerebral malaria) & 24 & 1 & 15 & 2 \\
\hline Recurring seizures & 38 & 1 & 6 & 1 \\
\hline Severe anemia $(\mathrm{Hb}<6 \mathrm{~g} / \mathrm{dl})$ & 143 & 24 & 35 & 0 \\
\hline Hyperparasitemia (> 5\%) & 104 & 1 & 28 & 0 \\
\hline Acute renal failure (Cre > 3 mg/dL) & 15 & 3 & 24 & 1 \\
\hline Liver dysfunction (ALT > 3x normal) & 79 & 7 & 28 & 3 \\
\hline Acidosis (serum bicarbonate $<5 \mathrm{mmol} / \mathrm{dL}$ ) & 10 & 2 & 20 & 1 \\
\hline Acute respiratory distress & 1 & 1 & 7 & 1 \\
\hline Severe vomiting & 51 & 5 & 15 & 0 \\
\hline Sudden cardiac arrest & 0 & 0 & 12 & 1 \\
\hline
\end{tabular}

* Including mixed infections.

case of severe malaria was attributed to $P$. malariae infection. Patients with monoinfections versus mixed infections were equally likely to be classified with severe malaria $(\mathrm{OR}=0.94$, $95 \%$ CI $=0.68-1.29$ ).

Among the 88 malaria-attributed deaths (5,811 patients with confirmed outcomes), 9 fatalities occurred in patients with $P$. vivax recorded as the only species present in blood film examinations. Table 5 lists the number of patients with each recorded clinical feature of severe malaria at the time of or soon after admission. There were no significant differences between $P$. falciparum and $P$. vivax patients with respect to reported clinical features, except for hyperparasitemia $(>3$ score), which was more common with $P$. falciparum $(P<$ $0.0001)$. The risk of death caused by severe malaria was $23 \%$ for $P$. falciparum (63/276, 1 outcome unknown), 25\% for $P$. vivax (9/36), and 31\% for mixed infections (16/52, 1 outcome unknown). Severe malaria patients with mixed infections were not significantly more likely to suffer a fatal outcome than those with monoinfections $(\mathrm{OR}=1.49,95 \% \mathrm{CI}=0.74$ 2.96). Splenic rupture was not reported in any patient who suffered a fatal outcome.

Table 6 presents the parasite scores of patients with $P$. falciparum or $P$. vivax monoinfections, stratified by three clinical groups: non-severe malaria; severe malaria, surviving; and severe malaria, not surviving. There was no significant difference in survival rates among severe malaria patients

TABLE 6

Parasite scores of $P$. falciparum and $P$. vivax monoinfections, stratified by three clinical classifications: non-severe malaria; severe malaria, surviving; and severe malaria, not surviving

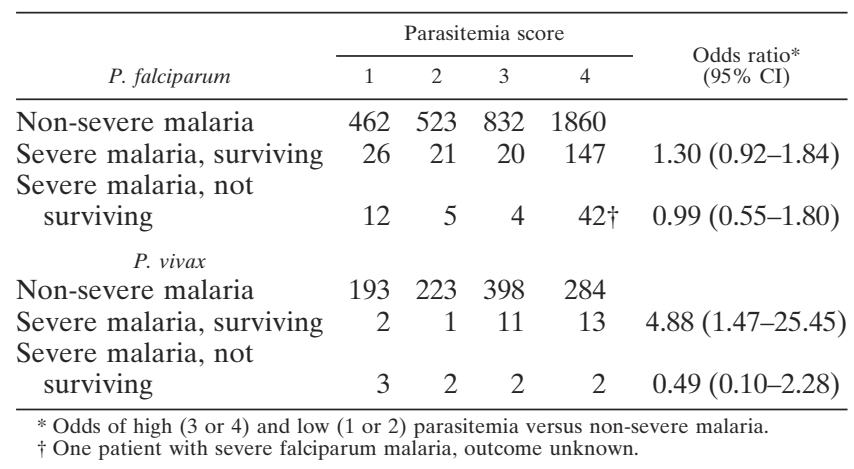

with $P$. falciparum versus $P$. vivax monoinfections $(\mathrm{OR}=$ $0.89 ; 95 \% \mathrm{CI}=0.37-2.15)$. Falciparum malaria patients with high parasitemia were not statistically more likely to either be classified as having severe malaria or not survive severe malaria compared with non-severe malaria patients $(\mathrm{OR}=1.30$, $95 \% \mathrm{CI}=0.92-1.84$ and $\mathrm{OR}=0.99,95 \% \mathrm{CI}=0.55-1.80$, respectively). Vivax malaria patients with high parasitemia were significantly more likely to be classified as having severe malaria $(\mathrm{OR}=4.88,95 \% \mathrm{CI}=1.47-24.45)$ but not more likely to suffer a fatal outcome from severe malaria $(\mathrm{OR}=$ $0.49,95 \%$ CI $=0.10-2.28$ ) compared with non-severe malaria patients.

Hospitalization risk and monthly distribution. The annual incidence of hospitalization for malaria in Jayapura District was $4.9,6.5$, and 6.3 per 1,000 person-years in 1998, 1999, and 2000, respectively. Figure 2 shows the number of malaria admissions at RSUP over the 36 months of reporting. The number of cases per month ranged between 66 and 248 (mean = 165). Falciparum malaria showed distinct seasonal peaks and troughs, whereas $P$. vivax hospitalizations remained relatively stable throughout the year. Months of greatest patient admission activity for falciparum malaria were April to June, a time coinciding with normal transition from wet to relatively drier months of the year.

\section{DISCUSSION}

Higher risk of malaria in Jayapura District lies mainly in sparsely populated rural areas, ${ }^{8}$ where greater transmission intensity and incidence of infection provides sufficient exposure for the rapid development and sustainability of clinical acquired immunity to falciparum malaria. ${ }^{18,19}$ Risk of severe disease may increase among residents with insufficient exposure precluding development of protective clinical immunity (i.e., being similar to non-immune individuals from nonendemic regions). Moreover, there may be segments in the general population more vulnerable to severe disease, particularly pregnant women and young children. ${ }^{20-22}$

The prevailing view among physicians and scientists has been that $P$. vivax infection, although long known as capable of causing death (especially by rupture of the spleen), results in an uncomfortable but generally benign course of disease. Indeed, vivax malaria has long been known as "benign tertian malaria." Historically, reports often attributed $P$. vivax fatali- 


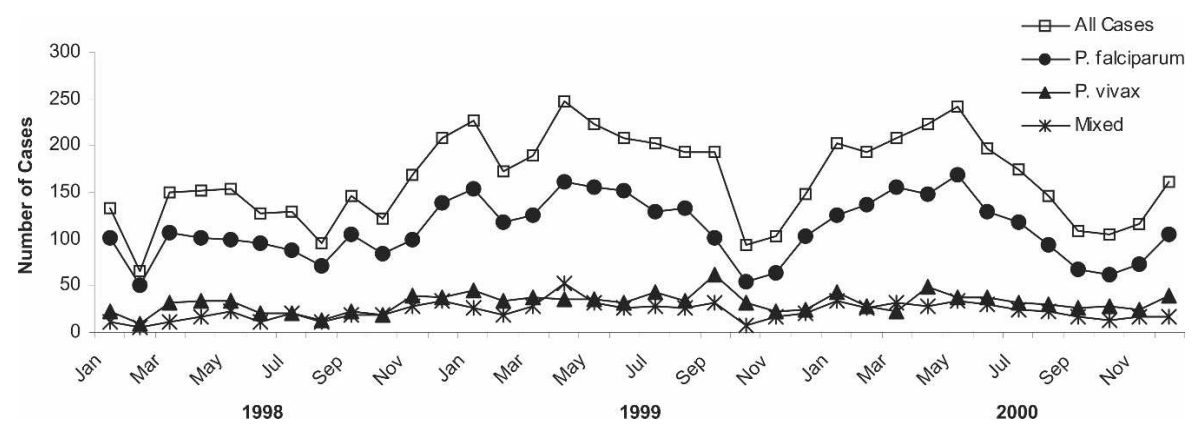

FIGURE 2. Monthly distribution of malaria cases by Plasmodium species admitted to Jayapura Hospital, 1998-2000.

ties to misdiagnosis. For example, a retrospective study of 222 fatal malaria cases in Tennessee in 1935 found equal numbers of deaths from $P$. falciparum and $P$. vivax, as reported by two separate departments. ${ }^{23}$ Clinical features of cases for which the author gained pertinent information were described as "cerebral in type," with no mention of splenic rupture. The author attributed the $P$. vivax deaths to misdiagnosis. The data from Jayapura similarly suggest a less benign infection. The observed risks of severe and fatal outcomes should be corroborated by prospective studies using definitive diagnostic protocols both for malaria and for ruling out concurrent infections by other pathogens.

We had no objective measure of the competencies of the microscopists at RSUP. Misdiagnosis of $P$. falciparum or cryptic mixed infections of $P$. falciparum and $P$. vivax as monoinfection by $P$. vivax represent potential pitfalls. ${ }^{24,25}$ However, we considered possible misclassification bias as likely to favor the diagnosis of $P$. falciparum: this representing the diagnosis of safety for the patient and consistency with the perceived etiology of severe falciparum malaria. In view of the direction of these biases, we considered our estimates of risk with vivax malaria to be conservative. Nonetheless, in areas where malaria is heavily endemic, malaria may be the likely diagnosis across a broad spectrum of other infectious diseases (e.g., meningococcal encephalitis, viral encephalidities, infectious pneumonias, and many others). In this study, we could not rule out these as underlying causes of severe and fatal disease with patent falciparum or vivax malaria.

Plasmodium falciparum was diagnosed in $67 \%$ of hospitalized patients, and $19 \%$ of hospitalizations were with vivax malaria (excluding mixed infections, $P$. vivax accounted for $14 \%$ of hospitalizations). This approximate $3: 1 \mathrm{P}$. falciparum: $P$. vivax ratio is only slightly higher than observed in many cross-sectional malaria surveys in the region. $6,7,10,11,18,19$ We do not know the ratio of plasmodia species over the period of this hospital review across the region, but the $19 \%$ of hospital admissions for malaria being caused by vivax malaria exceeded expectations for a supposedly benign infection. This was also true with regard to risk of severe disease: $7 \%$ of hospitalizations resulting from $P$. falciparum and 3\% for $P$. vivax. Among patients with severe disease, vivax proved as lethal as falciparum malaria, with case fatality rates of $25 \%$ and $23 \%$, respectively $(P=0.771)$.

Few published studies describe severe and fatal vivax malaria. Most of what we understand derives from induced infections in neurosyphilis patients or prison volunteers who were protected from life-threatening outcomes. Evidence from endemic areas lends support to the view that vivax malaria may be perhaps less benign than widely perceived. Basu and others ${ }^{26}$ reviewed 405 malaria admissions to hospital in Calcutta, mostly $P$. vivax, of which five cases were classified as severe, and Mehta and others ${ }^{27}$ identified 24 patients with acute renal failure associated with malaria, among which 3 cases were attributed to $P$. vivax monoinfection. Among 40 malaria-related deaths of travelers repatriated to the United States over a 20 -year period, 2 of these were attributed to $P$. vivax monoinfections. ${ }^{28}$ Numerous cases of clinical syndromes consistent with severe falciparum malaria caused by $P$. vivax monoinfection have been reported. ${ }^{29-37}$ However, all of these studies relied on microscopic diagnosis, and the high likelihood of misdiagnosis of mixed infections is well known. ${ }^{24,38,39}$ The severity of disease in such patients may be explained on the basis of a missed diagnosis of falciparum malaria.

A recent study, however, applied microscopic diagnostics complemented with polymerase chain reaction assays affirming the absence of $P$. falciparum among 11 severely ill malaria patients in India. ${ }^{40}$ These patients exhibited the syndromes of cerebral malaria, renal failure, circulatory collapse, severe anemia, hemoglobinurea, abnormal bleeding, acute respiratory distress syndrome, and jaundice. Among the nine fatal cases of vivax malaria recorded at RSUP, the case records listed the following syndromes: cerebral malaria (two), seizures (one), acute respiratory distress (one), acute renal failure (one), liver dysfunction (three), metabolic acidosis (one), sudden cardiac arrest (one) and high fever (one). If rupture of an enlarged spleen is the dominant life-threatening complication of vivax malaria, ${ }^{41}$ our study and others fail to corroborate that view. Instead, the presentation of cerebral manifestations, respiratory distress, and renal failure resembling severe falciparum malaria seems to be the more common presentation of severe $P$. vivax infection. Anstey and others ${ }^{42}$ have reported evidence of lung injury among patients with vivax malaria in Papua, Indonesia. Nonetheless, no study of severe vivax malaria has systematically excluded underlying bacterial or viral infections as the basis of severe disease.

Elevated risk of hospitalization and death with severe malaria among adults relative to children occurred at Jayapura Hospital between 1998 and 2000. Relative to their proportion in the general population $(68 \%)$, adults were overrepresented $(71 \% ; P=0.007)$ among hospitalized patients, whereas children ( $32 \%$ of population) were underrepresented among those hospitalized $(29 \% ; P<0.001)$. How- 
ever, the youngest children ( $\leq 4$ years), like adults, were over-represented among hospitalized malaria cases (16\% versus $12 \%, P<0.001)$. Children between the ages of 5 and 15 years seemed to be at lowest risk of hospitalization. This may be attributable to intrinsic factors related to host age or may be a product of differing exposure risk between age groups. For example, younger children may be required or more inclined to accompany their parents traveling into higher-risk areas, whereas older children may be left unattended in the city. However, when we examined the risk of severe disease among people having quantitatively equal risk of infection, adults were at significantly higher risk of severe disease and death. ${ }^{3,4}$ The greater risk of adults and older age children to severe disease and death has also been documented in other studies. $^{43-46}$

We found no increased risks of severe disease or death among pregnant women compared with non-pregnant women admitted to hospital. This contrasts with holoendemic Africa, where pregnant women and especially the fetuses of primigravid women are more susceptible to complicated malaria and death. ${ }^{21,47}$ Other studies of pregnant women and malaria outside of holoendemic Africa have documented elevated risk of hyper-infection, severe malaria, or death compared with non-pregnant women. ${ }^{48-52}$ However, other observations have suggested negligible to modestly increased ill effects of malaria on pregnant women and perinatal outcomes. ${ }^{53-57} \mathrm{Ko}-$ char and others ${ }^{54}$ reported a series of 441 severely ill malaria patients in India where the odds ratio of mortality among pregnant (59) versus non-pregnant (161) women was 1.32 (95\% CI $=0.66-2.58, P=0.417)$. Likewise, in the setting of RSUP, pregnancy was not a risk factor for severe malaria or a fatal outcome. In the absence of population pregnancy figures, we could not address the risk of hospitalization among pregnant versus non-pregnant women.

Important differences appeared between residents of urban or suburban areas versus those living in rural settings in Papua. Living in an urban setting carried greater risks of higher-grade parasitemia and a fatal outcome with severe malaria (Tables 3 and 4). However, rural residents had higher risks of gametocytemia, anemia, and severe malaria (Table 4). These differences largely mirrored those appearing between children and adults. The mean age of rural patients was 21 years compared with 23 years among urban/suburban residents $(P<0.001)$ and confounding by age may, in part, explain these findings. Residents of rural areas, especially children, appeared relatively susceptible to anemia and severe malaria, whereas city dwellers, particularly adults, appeared relatively susceptible to fatal outcomes with severe disease. These differences may be related to a backdrop of chronic heavy exposure to infection with onset of some degree of immune mitigation of disease in rural areas. We accept that most patients coming from rural areas represent the worstcase outcomes among their neighbors, and the sample thus over-represents the more severely ill.

In summary, our retrospective analysis of 5,936 admissions to the referral tertiary care hospital in the Jayapura District in northeastern Papua, Indonesia, revealed risk factors for severe and fatal disease among a diverse population living in hypo-endemic or hyper- to holoendemic settings. Infection by $P$. vivax apparently resulted in frequent hospitalizations, severe disease ( $3 \%$ of vivax admissions), and death $(25 \%$ of severely ill with vivax) by syndromes resembling those com- monly seen with falciparum malaria. Adults and very young children tended to be over-represented among the hospitalized, with older children under-represented. Likewise, although children were at a higher risk of severe disease, adults carried a much greater risk of death when severely ill. Pregnancy was not a significant risk factor for severe or fatal malaria among these patients. People living in the countryside were at greater risk of presenting with anemia and severe malaria compared with urban-dwellers, but rural populations were at a lower risk of death with severe malaria. Several diagnostic pitfalls preclude definitive conclusions regarding the pathophysiology of vivax malaria, and prospective studies with definitive diagnostics are needed to clarify the risk of severe and fatal disease accompanying infection by $P$. vivax in heavily endemic settings.

\section{Received May 6, 2007. Accepted for publication July 15, 2007.}

Acknowledgments: The authors gratefully acknowledge the advice and assistance of many officers in the provincial health service of Papua, especially W. Kalalo, Health Services Director, and Claudia Surjadjaja, health service liaison officer. We also appreciate the technical assistance of Agus Rahmat at US NAMRU-2 in Jakarta, and the valuable assistance of Rosye Tanjung, Patriot Karubuy, and Fabianus Giay in Jayapura. Robert W. Taylor at the Oxford University Clinical Research Unit in Hanoi provided a thoughtful review of the manuscript.

Financial support: This work was supported in part by the US Department of Defense Global Emerging Infections Surveillance and Response System.

The views and opinions expressed here are those of the authors and do not purport to represent those of the US Navy or of the US Department of Defense.

Authors' addresses: Mazie Barcus, 2061 Winged Foot Court, Reston, VA 20191. Hasan Basri, Family Health International, Komplek Ditjen PP4PL RI, Jl. Percetakan Negara No. 29, Jakarta 10560, Indonesia, E-mail: hbasri@fhi.or.id. Helena Picarima, Family Health International, Kota Jayapura, Papua 99920, Indonesia. C. Manyakori, R.S. Persahabatan, Jl. Persahabatan Raya, Rawamangun, Jakarta, Indonesia. Sekartui, Puslitbang Biomedis \& Farmasi, Jl. Percetakan Negara No. 29, Jakarta 10560, Indonesia. Iqbal Elyazar, Parasitology Department Program, U.S. NAMRU-2, American Embassy Jakarta, Unit 8132, FPO AP 96520-8132. Michael J. Bangs, Public Health and Malaria Control Department, Freeport, Jl. Kertajasa, Kuala Kencana, Papua 99920, Indonesia. Jason D. Maguire, Naval Medical Center Portsmouth, 620 John Paul Jones Circle, Portsmouth, VA 2370. J. Kevin Baird, Eijkman-Oxford Clinical Research Unit, Eijkman Institute, Jl. Diponegoro No. 69, Jakarta 10430, Indonesia.

\section{REFERENCES}

1. McGregor IA, 1987. Malarial immunity: current trends and prospects. Ann Trop Med Parasitol 81: 647-656.

2. McGregor IA, Wilson RJM, 1988. Specific immunity: acquired in man. Wernsdorfer WH, McGregor I, eds. Malaria: Principles and Practice of Malariology. Vol. I. London: Churchill Livingstone, 559-619.

3. Baird JK, Basri H, Weina P, Maguire JD, Barcus MJ, Picarema H, Elyazar IR, Ayomi E, 2003. Adult Javanese migrants to Indonesian Papua at high risk of severe disease caused by malaria. Epidemiol Infect 131: 791-797.

4. Baird JK, Masbar S, Basri H, Tirtokusumo S, Hoffman SL, 1998. Age-dependent susceptibility to severe disease caused by Plasmodium falciparum. J Infect Dis 178: 592-595.

5. Baird JK, Jones TR, Danudirgo EW, Basri H, Annis BA, Bangs MA, Wiady I, Masbar S, 1991. Age-dependent acquired immunity against Plasmodium falciparum among people with 2 years exposure to hyperendemic malaria. Am J Trop Med Hyg 45: $65-76$.

6. Baird JK, Purnomo, Basri H, Bangs MJ, Andersen EM, Jones 
TR, Masbar S, Harjosuwarno S, Subianto B, Arbani PR, 1993. Age-specific prevalence of Plasmodium falciparum among six populations with limited histories of exposure to endemic malaria. Am J Trop Med Hyg 49: 707-719.

7. Baird JK, 1998. 1998. Age-dependent characteristics of protection versus susceptibility to Plasmodium falciparum. Ann Trop Med Parasitol 92: 367-390.

8. Gunawan S, 1985. A review of the malaria situation in Irian Jaya. Bul Penelit Kesehat 13: 1-13.

9. Badan Pusat Statistik (BPS-Statistics Indonesia) and ORC Macro, 2004. Jayapura City Young Adult Reproductive Health Survey in 2002-2003. Calverton, MD: BPS-Statistics Indonesia and ORC Macro.

10. Taylor WR, Richie TL, Fryauff DJ, Picarima H, Ohrt C, Tan D, Braitman D, Murphy GS, Widjaja H, Tjitra E, Ganja A, Jones TR, Basri H, Berman J, 1999. Malaria prophylaxis using azithromycin: a double-blind, placebo-controlled trial in Irian Jaya, Indonesia. Clin Inf Dis 28: 74-81.

11. Ohrt C, Richie TL, Widjaja H, Shanks GD, Fitriadi J, Fryauff DJ, Handschin J, Tang D, Sandjaja B, Tjitra E, Hadiarso L, Watt G, Wignall FS, 1997. Mefloquine compared with doxycycline for the prophylaxis of malaria in Indonesian soldiers. A randomized, double-blind, placebo-controlled trial. Ann Intern Med 126: 963-972.

12. Slooff R, 1964. Observations on the Effect of Residual DDT House Spraying on Behaviour and Mortality in Species of the Anopheles punctulatus Group. Leydon: A. W. Sythoff.

13. Barcus MJ, Krisin, Elyazar IRF, Marwoto H, Richie TL, Basri H, Wiady I, Fryauff DJ, Maguire JD, Bangs MJ, Baird JK, 2003. Primary infection by Plasmodium falciparum or Plasmodium vivax in a cohort of Javanese migrants to Indonesian Papua. Ann Trop Med Parasitol 97: 565-574.

14. Burkot TR, Dye C, Graves PM, 1989. An analysis of some factors determining the sporozoite rates, human blood indexes, and biting rates of members of the Anopheles punctulatus complex in Papua New Guinea. Am J Trop Med Hyg 40: 229-234.

15. World Health Organization, 2000. Management of Severe Malaria. A Practical Handbook. Second edition. Geneva: World Health Organization.

16. Badan Pusat Statistik (BPS-Statistics Indonesia), 2001. Population of Papua: Results of the 2000 Population Census, Series L2.2.30. Jakarta, Indonesia: BPS.

17. World Health Organization, 1991. Basic Malaria Microscopy. Part I. Learner's Guide. Geneva: World Health Organization.

18. Baird JK, Krisin, Barcus MJ, Elyazar IR, Bangs MJ, Maguire JD, Fryauff DJ, Richie TL, Sekartuti, Kalalo W, 2003. Onset of clinical immunity to Plasmodium falciparum among Javanese migrants to Indonesian Papua. Ann Trop Med Parasitol 97: 557-564.

19. Krisin, Basri H, Fryauff DJ, Barcus MJ, Bangs MJ, Ayomi E, Marwoto H, Elyazar IR, Richie TL, Baird JK, 2003. Malaria in a cohort of Javanese migrants to Indonesian Papua. Ann Trop Med Parasitol 97: 543-556.

20. Crawley J, 2004. Reducing the burden of anemia in infants and young children in malaria-endemic countries of Africa: from evidence to action. Am J Trop Med Hyg 71 (suppl. 2): 25-34.

21. Van Geertruyden J-P, Thomas F, Erhart A, D'Alessandro U, 2004. The contribution of malaria in pregnancy to perinatal mortality. Am J Trop Med Hyg 71 (Suppl 2): 35-40.

22. Caulfield LE, Richard SA, Black RE, 2004. Undernutrition as an underlying cause of malaria morbidity and mortality in children less than five years old. Am J Trop Med Hyg 71 (Suppl 2): $55-63$.

23. Meleny HE, The problem of malaria mortality in the United States. Presidential address read before the American Society of Tropical Medicine, 32nd Annual Meeting, Baltimore, MD, November 19, 1936.

24. Brown AE, Kain KC, Pipithkul J, Webster HK, 1992. Demonstration by the polymerase chain reaction of mixed Plasmodium falciparum and $P$. vivax infections undetected by conventional microscopy. Trans R Soc Trop Med Hyg 86: 609-612.

25. Krudsood S, Wilairatana P, Mason DP, Treeprasertsuk S, Singhasivanon P, Looareesuwan S, 1999. Hidden Plasmodium falciparum infections. Southeast Asian J Trop Med Pub Hlth 30: 623-624.
26. Basu K, Das PK, Mondal T, Nandy A, Bhowmick PK, Addy M, 1998. Resurgence of malaria in Calcutta 1995: a hospital-based study. Indian J Pub Hlth 42: 50-52.

27. Mehta KS, Halankar AR, Makwana PD, Torane PP, Satija PS, Shah VB, 2001. Severe acute renal failure in malaria. $J$ Postgrad Med 47: 24-26.

28. Stoppacher R, Adams SP, 2003. Malaria deaths in the United States: case report and review of deaths, 1979-1998. J Forensic Sci 48: 404-408.

29. Beg MA, Khan R, Baig SM, Gulzar Z, Hussain R, Smego RA, 2002. Cerebral involvement in benign tertian malaria. Am J Trop Med Hyg 67: 230-232.

30. Mohapatra MK, Padhiary KN, Mishra DP, Sethy G, 2002. Atypical manifestations of Plasmodium vivax malaria. Indian J Malariol 39: 18-25.

31. Makkar RP, Monga SM, Gupta AK, 2002. Plasmodium vivax malaria presenting with severe thrombocytopenia. Braz J Infect Dis 6: 263-265.

32. Tanious MA, Kogelman L, McGovern B, Hassoun PM, 2001. Acute respiratory distress syndrome complicating Plasmodium vivax malaria. Crit Care Med 29: 665-667.

33. Kakar A, Bhoi S, Prakash V, Kakar S, 1999. Profound thrombocytopenia in Plasmodium vivax malaria. Diagn Microbiol Infect Dis 35: 243-244.

34. Patial RK, Kapoor D, Mokta JK, 1998. Cerebral dysfunction in vivax malaria: a case report. Indian J Med Sci 52: 159-160.

35. Valech N, Bagga A, Chandra J, Sharma D, 1992. Cerebral symptoms with P. vivax malaria. Indian Pediatr 29: 1176-1177.

36. Mishra VN, Singh D, 1989. Cerebral malaria by Plasmodium vivax. J Assoc Phys India 37: 411.

37. Verma KC, Magotra ML, 1976. Vivax cerebral malaria in Jammu. Indian Pediatr 13: 229-231.

38. McKenzie FE, Bossert WH, 1999. Multispecies Plasmodium infections of humans. J Parasitol 85: 12-18.

39. Snounou G, Viriyakosol S, Jarra W, Thaithong S, Brown KN, 1993. Identification of the four human malaria parasite species in field samples by the polymerase chain reaction and detection of a high prevalence of mixed infections. Mol Biochem Parasitol 58: 283-292.

40. Kochar DK, Saxena V, Singh N, Kochar SK, Kumar SV, Das A, 2005. Plasmodium vivax malaria. Emerg Infect Dis 11: 132-134.

41. Warrell DA, 2002. Clinical features of malaria. Warrell DA, Gilles HM, eds. Essential Malariology. Fourth edition. London: Arnold, 191-205.

42. Anstey NM, Handojo T, Pain MCF, Kenagnalem E, Tjitra E, Price RN, Maguire GP, 2007. Lung injury in vivax malaria: pathophysiological evidence for pulmonary vascular sequestration and post-treatment alveolar-capillary inflammation. $J$ Infect Dis 195: 589-596.

43. Mohanty S, Mishra SK, Pati SS, Pattnaik J, Das BS, 2003. Complications and mortality patterns due to Plasmodium falciparum malaria in hospitalized adults and children, Rourkela, Orissa, India. Trans R Soc Trop Med Hyg 97: 69-70.

44. Ejov MN, Tun T, Aung S, Lwin S, Sein K, 1999. Hospital-based study of severe malaria and associated deaths in Myanmar. Bull WHO 77: 310-314.

45. Reyburn H, Mbatia R, Drakeley C, Bruce J, Carneiro I, Olomi R, Cox J, Nyka WM, Lemnge M, Greenwood BM, Riley EM, 2005. Association of transmission intensity and age with clinical manifestations and case fatality of severe Plasmodium falciparum malaria. JAMA 293: 1461-1470.

46. Rabe C, Paar WD, Knopp A, Munch J, Musch A, Rockstroh J, Martin S, Sauerbruch T, Dumoulin FL, 2005. [Malaria in the emergency room. Results of emergency treatment of 137 patients with symptomatic malaria]. Dtsch Med Wochenschr 130: 145-149.

47. Steketee RW, Nahlen BL, Paris ME, Menendez C, 2001. The burden of malaria in pregnancy in malaria endemic areas. $\mathrm{Am}$ J Trop Med Hyg 64: 28-35.

48. Nosten F, ter Kuile F, Maelankirri L, Decludt B, White NJ, 1991. Malaria during pregnancy in an area of unstable endemicity. Trans $R$ Soc Trop Med Hyg 85: 424-429.

49. Luxemburger C, Ricci F, Nosten F, Raimond D, Bathet S, White NJ, 1997. The epidemiology of severe malaria in an area of low transmission in Thailand. Trans R Soc Trop Med Hyg 91: 256-262. 
50. Kochar DK, Thanvi I, Joshi A, Shubhakaran, Agarwal N, Jain N, 1999. Mortality trends in falciparum malaria-effect of gender difference and pregnancy. J Assoc Physicians India 47: 774778.

51. Singh N, Suhkla MM, Sharma VP, 1999. Epidemiology of malaria in pregnancy in central India. Bull WHO 77: 567-572.

52. Hammerich A, Campbell OMR, Chadramohan D, 2002. Unstable malaria transmission and maternal mortality-experiences from Rwanda. Trop Med Int Hlth 7: 573-576.

53. Das LK, 2000. Malaria during pregnancy and its effects on the foetus in a tribal area of Koraput District, Orissa. Indian $J$ Malariol 37: 11-17.

54. Kochar DK, Shubhakaran, Kumawat BL, Kochar SK, Halwai M, Makkar RK, Joshi A, Thanvi I, 2002. Cerebral malaria in Indian adults: a prospective study of 441 patients from Bikaner, north-west India. J Assoc Physicians India 50: 234-241.

55. Cot M, Brutus L, Pinell V, Ramaroson H, Raveloson A, Rabeson D, Rakotonjanabelo AL, 2002. Malaria prevention during pregnancy in unstable transmission areas: the highlands of Madagascar. Trop Med Int Health 7: 565-572.
56. Elghazali G, Adam I, Hamad A, El-Bashir MI, 2003. Plasmodium falciparum infection during pregnancy in an unstable transmission area in eastern Sudan. East Mediter Health J 9: 570580.

57. Adam I, A-Elbasit IE, Salih I, Elbashir MI, 2005. Submicroscopic Plasmodium falciparum infections during pregnancy in an area of Sudan with low intensity of malaria transmission. Ann Trop Med Parasitol 99: 339-344.

\section{APPENDIX 1}

The plus system for enumerating parasites on a thick blood film

$\begin{array}{cl}+ & 1-10 \text { parasites per } 100 \text { thick film fields } \\ ++ & 11-100 \text { parasites per } 100 \text { thick film fields } \\ +++ & 1-10 \text { parasites per single thick film field } \\ ++++ & \text { More than } 10 \text { parasites per single thick film field }\end{array}$

Source: Basic Malaria Microscopy: Part 1. Learner's Guide. World Health Organization. 